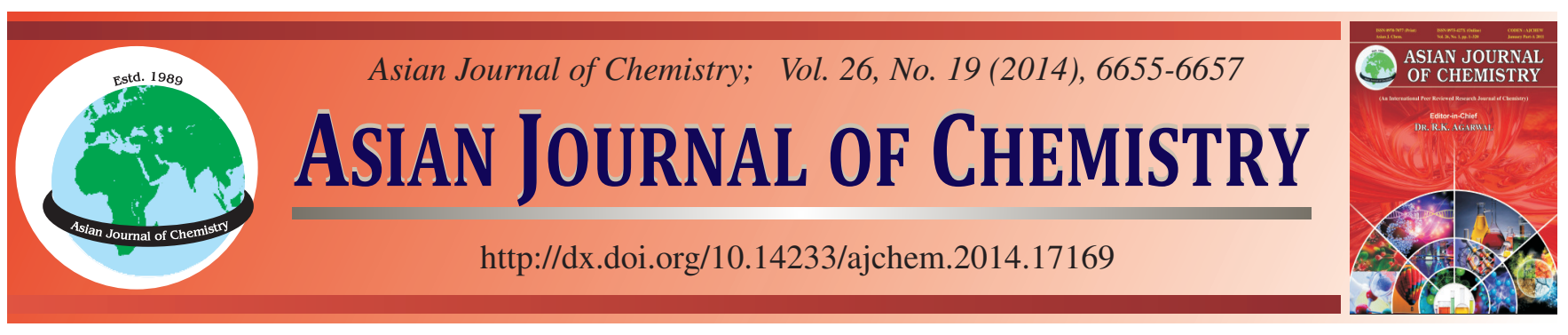

\title{
Facile Preparation of 6-(Aminomethyl)isoindolin-1-one Realizing Complete Reduction of Double Aromatic Cyano Groups
}

\author{
Lei BI ${ }^{1, *}$, Chenchao Fu ${ }^{1}$ and LeI YaO ${ }^{2, *}$
}

${ }^{1}$ School of Chemistry and Chemical Engineering, Anhui University of Technology, 59 Hudong Road, Maanshan 243002, Anhui, P.R. China ${ }^{2}$ School of Pharmacy, Yantai University, 32 Qingquan Road, Yantai, Shandong 264005, P.R. China

*Corresponding authors: E-mail: lei_bi@hotmail.com; yaoleiytu@163.com

6-(Aminomethyl)isoindolin-1-one is a key intermediate enroute to many investigational therapeutic agents. The need for it prompts a concise synthesis, which includes; (1) cyanation without using costly transition metal catalysts; (2) complete hydrogenation of the resulting dicyanide. This synthetic route emphasizes high atom-efficiency and simple operation. 5-(Aminomethyl)isoindolin-1-one, a structural analogue, is synthesized via this route as well.

Keywords: Isoindoline, Complete reduction, Dicyanide.

\section{INTRODUCTION}

Isoindoline is a [6,5] fused bicyclic nitrogen heterocyle. As such, it has been found in the structures of numerous natural products $^{1,2}$. At the same time, various small molecule therapeutics have incorporated this structure into their design as well $^{3,4}$. Among them, thalidamide could arguably be the most famous (or infamous) case.

This trend has continued in the new century. The pharmaceutical industry has extended the application of this structural motif on newer molecular targets such as chemokine receptors ${ }^{5}$ and histamine- 3 receptor ${ }^{6}$. The intended therapeutic areas include cancer ${ }^{7}$ as well as other life-threatening diseases ${ }^{8}$. In particular, the isoindoline structure studied in these unrelated research programs, from different corporations, could be categorized as multi-N-substituted 6-(aminomethyl) isoindolin1 -one. Nonetheless, the previously reported syntheses to this core structure are lengthy, utilizing reactions such as reductive amination or $[2+2+2]$ cycloaddition ${ }^{9}$. Typically, each individual synthesis is case specific and for screening purpose only (at the scale of milligrams). We herein report a concise and general synthesis of 6-(aminomethyl)isoindolin-1-one, applicable in large scale.

\section{EXPERIMENTAL}

Chemicals were either laboratory prepared or purchased from local vendors. Melting points were uncorrected and were taken in open glass capillaries using an INESA WRS-1B digital melting point apparatus. The IR spectra were recorded on a Perkin Elmer Spectrum 65 FT-IR spectrophotometer in $\mathrm{KBr}$ pellets. The ${ }^{1} \mathrm{H}$ and ${ }^{13} \mathrm{C}$ NMR spectra were recorded on a Bruker DRX-300 instrument using deuterated dimethyl sulfoxide (DMSO- $d_{6}$ ) as the solvent and tetramethylsilane (TMS) as the internal standard. The mass spectra were recorded on an agilent, 1200 HPLC-6120 MS spectrometer. Elemental analysis was performed on a Perkin Elmer PE 2400II CHNS/O instrument. The reaction progress was monitored by using silica gel GF254, precoated TLC plates $(0.2 \mathrm{~mm}$ thickness $)$ and visualized under UV light (254 and $365 \mathrm{~nm}$ ) and by iodine vapor.

Synthesis of 6-(aminomethyl)isoindolin-1-one hydrochloride

Step 1: To a 2 L round-bottom flask, 2,5-dibromobenzoic acid $(250 \mathrm{~g}, 0.90 \mathrm{~mol})$ in $\mathrm{MeOH}(2 \mathrm{~L})$ and concentrated $\mathrm{H}_{2} \mathrm{SO}_{4}$ $(18.4 \mathrm{~g}, 0.19 \mathrm{~mol})$ were added. The mixture was refluxed overnight before cooled to room temperature. The resulting precipitate was then filtered, washed with cold methanol and dried under vacuum. It yielded $203.6 \mathrm{~g}$ methyl 2,5-dibromobenzoate as a yellow solid. To a $2 \mathrm{~L}$ round-bottom flask was added 2,5-dibromobenzoate (198.2 g, $0.68 \mathrm{~mol})$ in $1 \mathrm{~L}$ dry DMF. CuCN (122 g, $1.36 \mathrm{~mol})$ and NaI (22.8 g, $0.15 \mathrm{~mol})$ were introduced next. The mixture was stirred overnight at $130{ }^{\circ} \mathrm{C}$ under nitrogen atmosphere. After the reaction was complete, it was extracted with ethyl acetate $(500 \mathrm{~mL} \times 3)$, washed with water $(500 \mathrm{~mL})$ and purified over silica gel (PE/ EtOAc $=5 / 1)$ to give $95.2 \mathrm{~g}$ methyl 2,5-dicyanobenzoate as a brown solid (yield: $75.1 \%$ ). 
Step 2: To a 5 L round-bottom flask were added methyl 2,5-dicyanobenzoate $(93.3 \mathrm{~g}, 0.50 \mathrm{~mol})$ and Raney-Ni (180 g, wet), suspended in $\mathrm{NH}_{3} / \mathrm{MeOH}(2.5 \mathrm{~L})$. The mixture was stirred overnight at room temperature under $\mathrm{H}_{2}$ at $35 \mathrm{psi}$. The mixture was filtered and washed with $\mathrm{MeOH}(2 \mathrm{~L})$. The filtrate was concentrated and purified over silica gel $(\mathrm{DCM} / \mathrm{MeOH}=10 / 1)$ to give 6-(aminomethyl)isoindolin-1-one as a pale-yellow solid. It was then dissolved in $\mathrm{HCl} / \mathrm{MeOH}$ and sirred overnight at room temperature. The solution was concentrated, washed with methyl $t$-butyl ether and dried under vacuum to give 6(aminomethyl)isoindolin-1-one hydrochloride as a white solid (70.6 g, yield: $71.1 \%$ ): m.p. $155-157{ }^{\circ} \mathrm{C}$; Anal. Calcd. for $\mathrm{C}_{9} \mathrm{H}_{10} \mathrm{~N}_{2} \mathrm{O}: \mathrm{C}, 66.65 ; \mathrm{H}, 6.21 ; \mathrm{N}, 17.27$. Found: C, 66.62; H, 6.23; N, 17.30. IR $\left(\mathrm{KBr}, \mathrm{v}_{\max }, \mathrm{cm}^{-1}\right): 3435(\mathrm{~N}-\mathrm{H}), 1685(\mathrm{C}=\mathrm{O})$; ${ }^{1} \mathrm{H}$ NMR $\left(300 \mathrm{MHz}, \mathrm{DMSO}-d_{6}, \delta / \mathrm{ppm}\right): 8.68(1 \mathrm{H}, \mathrm{s}, \mathrm{CONH})$, $8.61\left(3 \mathrm{H}, \mathrm{s},{ }^{+} \mathrm{NH}_{3}\right), 7.83(1 \mathrm{H}, \mathrm{s}$, aromatic), 7.72-7.74 $(1 \mathrm{H}, \mathrm{d}$, $J=6 \mathrm{~Hz}$, aromatic), 7.62-7.60 $(1 \mathrm{H}, \mathrm{d}, J=6 \mathrm{~Hz}$, aromatic), $4.39\left(2 \mathrm{H}, \mathrm{s}, \mathrm{CH}_{2}\right), 4.14-4.10\left(2 \mathrm{H}, \mathrm{q}, J=3 \mathrm{~Hz}, \mathrm{CH}_{2}\right) .{ }^{13} \mathrm{C} \mathrm{NMR}$ (75 MHz, DMSO- $\left.d_{6}, \delta / \mathrm{ppm}\right): 169.6,143.2,134.3,131.7$, 130.1, 128.9, 127.3, 48.3, 42.8. MS $(\mathrm{m} / \mathrm{z}): 163.1\left([\mathrm{~m}+1]^{+}\right)$.

\section{Synthesis of 5-(aminomethyl)isoindolin-1-one hydrochloride}

Step 1: To a 2 L round-bottom flask, 2,4-dibromobenzoic acid $(250 \mathrm{~g}, 0.90 \mathrm{~mol})$ in $\mathrm{MeOH}(2 \mathrm{~L})$ and concentrated $\mathrm{H}_{2} \mathrm{SO}_{4}$ $(18.4 \mathrm{~g}, 0.19 \mathrm{~mol})$ were added. The mixture was refluxed overnight before cooled to room temperature. The resulting precipitate was then filtered, washed with cold methanol and dried under vacuum. It yielded $213.6 \mathrm{~g}$ methyl 2,4-dibromobenzoate as a yellow solid. To a $2 \mathrm{~L}$ round-bottom flask was added 2,4-dibromobenzoate (200.7 g, $0.69 \mathrm{~mol})$ in $1 \mathrm{~L}$ dry DMF. CuCN (123.8 g, $1.38 \mathrm{~mol})$ and NaI (22.8 g, $0.15 \mathrm{~mol})$ were introduced next. The mixture was stirred overnight at $160{ }^{\circ} \mathrm{C}$ under nitrogen atmosphere. After the reaction was complete, it was extracted with ethyl acetate $(500 \mathrm{~mL} \times 3)$, washed with water $(500 \mathrm{~mL})$ and purified over silica gel (PE/ EtOAc $=5 / 1)$ to give $93.5 \mathrm{~g}$ methyl 2,4-dicyanobenzoate as a brown solid (yield: $72.8 \%$ ).

Step 2: To a $5 \mathrm{~L}$ round-bottom flask were added methyl 2,4-dicyanobenzoate (93.1 g, $0.50 \mathrm{~mol})$ and Raney$\mathrm{Ni}$ (180 g, wet), suspended in $\mathrm{NH}_{3} / \mathrm{MeOH}(2.5 \mathrm{~L})$. The mixture was stirred overnight at room temperature under $\mathrm{H}_{2}$ at 35 psi. The mixture was filtered and washed with $\mathrm{MeOH}(2 \mathrm{~L})$. The filtrate was concentrated and purified over silica gel $(\mathrm{DCM} / \mathrm{MeOH}=10 / 1)$ to give 5-(aminomethyl)isoindolin-1-one as a pale-yellow solid. It was then dissolved in $\mathrm{HCl} / \mathrm{MeOH}$ and sirred overnight at room temperature. The solution was concentrated, washed with methyl $t$-butyl ether and dried under vacuum to give 5(aminomethyl)isoindolin-1-one hydrochloride as a white solid (75.8 g, yield: $76.5 \%$ ): m.p. $171-173{ }^{\circ} \mathrm{C}$; Anal. Calcd. for $\mathrm{C}_{9} \mathrm{H}_{10} \mathrm{~N}_{2} \mathrm{O}$ : C, 66.65; H, 6.21; N, 17.27. Found: C, 66.67; $\mathrm{H}, 6.18 ; \mathrm{N}, 17.32$. IR $\left(\mathrm{KBr}, \mathrm{v}_{\max }, \mathrm{cm}^{-1}\right): 3430(\mathrm{~N}-\mathrm{H}), 1675$ $(\mathrm{C}=\mathrm{O}) ;{ }^{1} \mathrm{H}$ NMR $\left(300 \mathrm{MHz}, \mathrm{DMSO}-d_{6}, \delta / \mathrm{ppm}\right): 8.67(1 \mathrm{H}$, $\mathrm{s}, \mathrm{CONH}), 8.64\left(3 \mathrm{H}, \mathrm{s},{ }^{+} \mathrm{NH}_{3}\right), 7.71-7.69(2 \mathrm{H}, \mathrm{d}, J=6 \mathrm{~Hz}$, aromatic), 7.63-7.61 (1H, d, $J=6 \mathrm{~Hz}$, aromatic), $4.39(2 \mathrm{H}$, $\left.\mathrm{s}, \mathrm{CH}_{2}\right), 4.15-4.11\left(2 \mathrm{H}, \mathrm{q}, J=3 \mathrm{~Hz}, \mathrm{CH}_{2}\right) .{ }^{13} \mathrm{C}$ NMR $(75$ MHz, DMSO- $\left.d_{6}, \delta / \mathrm{ppm}\right): 175.2,145.3,133.9,125.6,124.3$, 123.9, 123.8, 51.7, 45.8. MS $(\mathrm{m} / \mathrm{z}): 163.2\left([\mathrm{~m}+1]^{+}\right)$.

\section{RESULTS AND DISCUSSION}

On account of concerns on commercial availability and cost, 2,5-dibromobenzoic acid was chosen as the starting material, converted to its methyl ester by Fisher esterification. Since the ester group was electron-withdrawing, methyl 2,5dibromobenzoate underwent an $S_{N} A$ r reaction with copper(I) cyanide and sodium iodide at elevated temperature (Fig. 1). Rarely as in this instance, cyanation did not require a transitionmetal coupling catalyst, for example, palladium with suitable ligands ${ }^{10,11}$. Methyl 2,5-dicyanobenzoate was prepared by this method conveniently and economically.

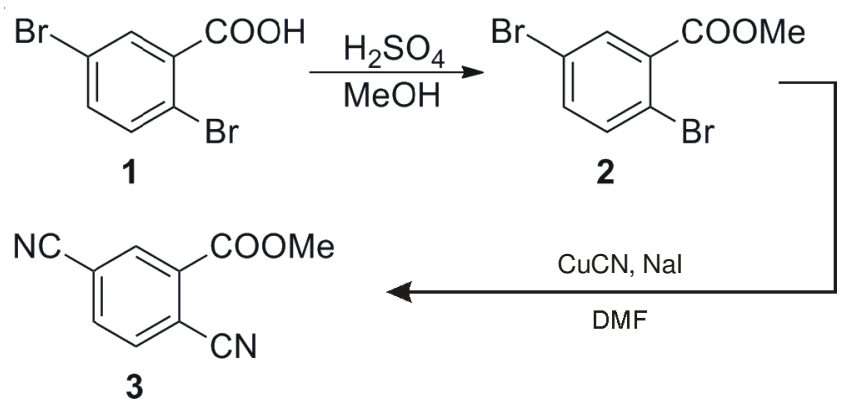

Fig. 1. Synthesis of methyl 2,5-dicyanobenzoate

Next, we envisioned by thorough reduction of both cyano groups to amino groups, the target molecule would be furnished in a single step ${ }^{12,13}$. However, this transformation turned out to be troublesome. After numerous attempts, multiple products were consistently found by TLC, supposedly as the result of incomplete reduction.

This hurdle prompted us to take close examination of the proposed conversion. Cyanide (carbon-nitrogen triple bond) reduction had been a long-time common endeavor, with various means developed to suit different needs ${ }^{14,15}$. It went through the stage of imine, which was also nucleophilic and could further react with fully reduced amine, resulting in secondary or even tertiary amines as by-products. On the other hand, astonishingly, the occurrence of concurrent reduction of two or more cyano groups was sporadic in the literature ${ }^{16}$ and it is particularly difficult to find aromatic cases (cyano groups on aromatic rings), if not unforeseen.

TABLE-1

REACTION CONDITIONS FOR THE DICYANIDE REDUCTION

\begin{tabular}{ccl}
\hline Entry & Condition & \multicolumn{1}{c}{ Result } \\
\hline 1 & $\mathrm{BH}_{3} \cdot \mathrm{THF}$ & Amide bond reduced as well \\
2 & $\mathrm{CoCl}_{6}, \mathrm{NaBH}_{4}$ & Multiple by-products, partial reduction \\
3 & $\mathrm{Pd} / \mathrm{C}, \mathrm{H}_{2}$ & Multiple by-products, partial reduction \\
4 & Raney Ni, 0.1 eq, $\mathrm{H}_{2}$ & Multiple by-products, partial reduction \\
5 & Raney Ni, 0.5 eq, $\mathrm{H}_{2}$ & Desired product \\
\hline
\end{tabular}

We thus did screening on the reduction conditions (Table-1) From the table, hydride sources, for example, boron hydride (entry 1) reduced not only nitrile but also the amide group in the desired product. Similarly, the use of $\mathrm{LiAlH}_{4}$ was eliminated. Molecular hydrogen (entries 2-5) was then chosen as the reducing source given the fact that ester or amide would stay intact ${ }^{17}$ with $\mathrm{H}_{2}$. However, in situ generation of hydrogen 
(entry 2) or direct hydrogenation (entry 3 ) both led to a mixture of as a result of incomplete reduction (vide supra). Further analysis indicated that with two or more cyano groups, unless all groups were converted into amino groups in a rather smooth fashion, partial reduction of any cyano group would lead to undesired by-products. Thus, the careful selection of reducing agents was key to the desired transformation ${ }^{18}$. Arguably, reduction took preference at position a for steric reasons. The highly reactive Raney nickel was employed as the hydrogenation catalyst. When the catalyst loading was increased from 0.1 eq to $0.5 \mathrm{eq}$, clean transformation to the title compound was finally achieved (Fig. 2).

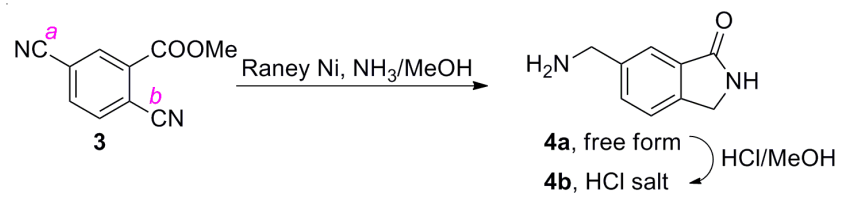

Fig. 2. Synthesis of 6-(aminomethyl)isoindolin-1-one hydrochloride

As a structural analogue, 5-(aminomethyl)isoindolin-1one (refer to Experimental) was also synthesized using the same synthetic scheme for later medicinal chemistry development.

\section{Conclusion}

Fast assembly of the target molecule has been achieved. In order to fully reduce multiple cyano groups, higher catalyst loading is necessary to avoid by-products from insufficient reduction. A palladium catalyst is not indispensable to enable the preceding cyanation step in our cases.

Altogether, we have developed a straight-forward synthesis for 6-(aminomethyl)isoindolin-1-one and 5-(aminomethyl)isoindolin-1-one. The procedure described herein satisfies process requirement with simple operation and relatively low cost, making it suitable for further development.

\section{ACKNOWLEDGEMENTS}

This project is supported by Natural Science Research Program for Higher Education, Key Program, Educational Commission of Anhui Province, China (Grant No. KJ2013A062) and Training Programs of Innovation and Entrepreneurship for College Students of Anhui Province, China (Grant No. AH201310360280).

\section{REFERENCES}

1. E. Valencia, A.J. Freyer, M. Shamma and V. Fajardo, Tetrahedron Lett., 25, 599 (1984).

2. E. Valencia, V. Fajardo, A.J. Freyer and M. Shamma, Tetrahedron Lett., 26, 993 (1985).

3. T.L. Stuk, B.K. Assink, D.T. Bates, D.T. Erdman, V. Fedij, S.M. Jennings, J.A. Lassig, R.J. Smith and T.L. Smith, Org. Process Res. Dev., 7, 851 (2003).

4. B. Portevin, C. Tordjman, P. Pastoureau, J. Bonnet and G. De Nanteuil, J. Med. Chem., 43, 4582 (2000).

5. Y. Zhou, E. Bourque, Y. Zhu, E. Mceachern, C. Harwig, R. Skerlj, G. Bridger, T.-S. Li and M. Metz, Chemokine Receptor Binding Compounds, U.S. Patent WO/2007/022371 (2007).

6. D. Zhou and J. Gross, Isoquinolinyl and Isoindolinyl Derivatives as Histamine-3 Antagonists, U.S. Patent WO/2009/036144 (2009).

7. G. Muller and A. Ruchelman, Isoindoline Compounds for Use in the Treatment of Cancer, U.S. Patent WO/2010/053732 (2010).

8. G. Muller, R. Chen and A. Ruchelman, 5-Substituted Isoindoline Compounds, U.S. Patent WO/2008/027542 (2008).

9. D.L. Priebbenow, S.G. Stewart and F.M. Pfeffer, Org. Biomol. Chem., 9, 1508 (2011).

10. J. Harris, S. Neelamkavil, B. Neustadt, C. Boyle, H. Liu, J. Hao, A. Stamford, S. Chackalamannil and W. Greenlee, Bicyclic Heterocycle Derivatives and Use Thereof as Gpr119 Modulators, U.S. Patent WO/ 2009/143049 (2009).

11. G.W. Muller and A.L. Ruchelman, Isoindoline Compounds and Methods of Their Use, U.S. Patent 8222249 (2012).

12. M.D. Clift and R.B. Silverman, Bioorg. Med. Chem. Lett., 18, 3122 (2008).

13. N. Wurtz, E. Priestley, D. Cheney, P. Glunz, X. Zhang, V. Ladziata, B. Parkhurst and L. Mueller, Macrocyclic Factor Viia Inhibitors Useful as Anticoagulants, U.S. Patent WO/2008/079836 (2008).

14. X. Zhang, A.A. Nirschl, Y. Zou and E.S. Priestley, Phenylglycinamide and Pyridylglycinamide Derivatives Useful as Anticoagulants, U.S. Patent WO/2007/002313 (2007).

15. D.C.M. Leysen, O.R. Defert, J.O.A. De Kerpel, E.P.P.R. Fourmaintraux, P. Arzel and G.J.H. De Wilde, Kinase Inhibitors, U.S. Patent WO/2005/ 082367 (2005).

16. J. Corsi, S.E. Diamond, J.E. Galle, F. Mares and F.J. Regina, Selective Hydrogenation of Aliphatic Dinitriles to Omega-Aminonitriles in Ammonia with Supported, Finely Dispersed Rhodium-Containing Catalyst, U.S. Patent US4601859 A (1986).

17. M. Laronze, M. Boisbrun, S. Léonce, B. Pfeiffer, P. Renard, O. Lozach, L. Meijer, A. Lansiaux, C. Bailly, J. Sapi and J.-Y. Laronze, Bioorg. Med. Chem., 13, 2263 (2005).

18. T.D. Nelson, C.R. LeBlond, D.E. Frantz, L. Matty, J.V. Mitten, D.G. Weaver, J.C. Moore, J.M. Kim, R. Boyd, P.-Y. Kim, K. Gbewonyo, M. Brower, M. Sturr, K. McLaughlin, D.R. McMasters, M.H. Kress, J.M. McNamara and U.H. Dolling, J. Org. Chem., 69, 3620 (2004). 